\title{
La transformación del presente en la narrativa española contemporánea. Una propuesta: la generación Nocilla
}

\author{
Violeta Ros Ferrer \\ UNIVERSITAT DE VALENCIA·Violeta.ros@uv.es
}

Becaria de investigación en el departamento de Filología Española de la Universitat de València, prepara su tesis doctoral sobre las representaciones de la Transición en la cultura española reciente, bajo la dirección de Joan Oleza.

Resumen: En el marco de la era de la información, algunas formas narrativas pueden ser pensadas como el síntoma literario de un cambio en las formas de producir y percibir la cultura. Desde esta perspectiva, se hace urgente el estudio de la influencia de la tecnología y los medios de comunicación en la evolución de ciertas tendencias de la narrativa en el contexto de la España de la primera década del siglo XXI. Este artículo propone la presentación y análisis de los efectos estéticos e ideológicos de la producción literaria de la generación Nocilla en este contexto, así como la reflexión en torno las circunstancias que pueden haber facilitado la aparición y consolidación de la propuesta narrativa de estos autores.

Palabras Clave: Narrativa, posmodernidad, canon, generación Nocilla, cambio cultural.

\begin{abstract}
Within the frame of the Information Age, certain kind of literary fiction could be understood as a synthom of the change happened in the ways of producing and perceiving culture. From this perspective, a study of the influence of technology and media in spanish 21 st century fiction is needed. In these terms, this paper presents generación Nocilla's literary production and considers its ideological and aesthetic effects in this context. It also considers the circumstances that might have provided the consolidation of this particular literary agenda.
\end{abstract}

Key Words: Narrative, postmodernism, canon, Nocilla generation, culture change. 
"Cada sociedad cultural tiene las novedades que se merece" UMBERTO ECO

\section{Introducción. Cuestionar el canon.}

Partimos de una declaración de intenciones: pensar la relación de la narrativa española contemporánea con su presente y desde el presente. El reto que aquí asumimos es el de interpretar y medir el significado y las consecuencias de la influencia que la aparición de cierto tipo de novedades literarias ha tenido en el ámbito de nuestra narrativa contemporánea. El pretexto, la presentación de la propuesta literaria de un grupo de autores surgida y desarrollada en el contexto de la narrativa española a lo largo de la última década: la generación Nocilla. El objetivo, la reflexión en torno a la transcendencia real de esta propuesta en este contexto, más allá del fenómeno puntual.

En el marco de la llamada Era de la Información ${ }^{1}$, en el que se está operando una transformación radical en las formas de producción y recepción cultural, el interés de esta propuesta trasciende la mera voluntad de ensalzar o denostar el producto, propia de una cierta crítica literaria. Más allá de la afinidad o el rechazo estético e ideológico que esta propuesta provoque en el público general lector, está el hecho de que su análisis permite hablar de una serie de contradicciones centrales en las reflexiones sobre la evolución de nuestro sistema cultural y, en consecuencia, del sistema literario que lo acompaña.

Últimamente, parece haberse convertido en una urgencia la pregunta por el modelo cultural surgido y desarrollado en España a lo largo del periodo democrático. Y algunas de las respuestas que esta pregunta suscita apuntan hacia una cierta desconfianza con respecto

\footnotetext{
${ }^{1}$ De las múltiples formas que ha sugerido la crítica cultural para referirse al periodo actual desde las consideraciones de la influencia de los medios tecnológicos hemos escogido, de momento y por una cuestión metodológica, la sugerida por el profesor Manuel Castells. Esta la elección se debe, fundamentalmente, a la importante dimensión sociológica que Castells otorga al término en su obra La era de la información. Economía sociedad y cultura (Castells, 1999). Joan Oleza, en sus ensayos sobre el cambio cultural hace un repaso de los diversos nombres con los que se ha caracterizado el periodo actual: "A la vuelta del fin de siglo [...] la intensidad y la sistematicidad de los trabajos orientados a caracterizar esta nueva época han comenzado a dibujar con mayor seguridad sus líneas de fuerza, hasta el punto de que si bien muchos mantienen la utilidad de la palabra Postmodernidad para caracterizarla, otros han comenzado a renombrarla tratando de destacar bien su relación con la Modernidad (tan polémica y oportunamente planteada por Habermas en 1981), bien sus rasgos más caracterizadores: Sociedad Postindustrial se anticipó a llamarla Daniel Bell (1973); Hardt y Negri han hablado de una nueva forma de Imperio (2005) y Zygmunt Bauman de una Modernidad Líquida (2000), frente a la ya disuelta Modernidad sólida; como Soft Modernity la ha caracterizado Niguel Thrift (1997), como Tardomodernidad ("Late Modern Age") Anthony Giddens, (1997); como Segunda Modernidad, Ulrich Beck (1992), y otros han hablado de Transmodernidad, Alta Modernidad o Era de la Globalización. Manuel Castells (2005), autor de la primera gran enciclopedia sociológica con vocación abarcadora, proponía llamarla la Era de la Información y definir la configuración social a la que da lugar como la Sociedad Red" (Oleza, 2012:303).
} 
a ese modelo; hacia la desconfianza con respecto a un modelo de cultura oficial progresista y bienpensante, que parece haber acomodado el pensamiento crítico mayoritario a una postura autocomplaciente en forma de columna en El País o de novela sobre la Guerra Civil $^{2}$.

La pregunta por la naturaleza de nuestro modelo cultural —o su cuestionamientotambién invita a pensar sobre la gran influencia que el desarrollo de las sociedades neoliberales ha tenido en la emergencia de nuevas subjetividades a lo largo de las últimas décadas. En España, el proceso de neoliberalización político y económico desarrollado a lo largo de las últimas tres décadas parece haber desencadenado, hoy, otro proceso distinto: un proceso de transformación, de cambio cultural, al que, por supuesto, la literatura no puede, ni debe, escapar. Esta transformación cultural ha sido propiciada por unas condiciones políticas, económicas, ideológicas y materiales determinadas cuyo alcance resulta todavía difícil definir con precisión. No obstante, y afrontando la dificultad de enunciar cualquier discurso cultural - y, por extensión, literario- al margen de estas condiciones, no puede obviarse el hecho de que las consecuencias de una transformación en lo cultural y en lo subjetivo tendrá, inevitablemente, repercusiones en la reformulación del lugar desde el que las nuevas generaciones enunciarán su literatura. Es el interés por estas reformulaciones concretas lo que aquí nos convoca.

Surgen, en este punto, una serie de preguntas: ¿Cuáles son los factores concretos propiciados por la consolidación del sistema neoliberal que inciden en la conformación de estas nuevas subjetividades? ¿En qué se distinguen estas nuevas formas de subjetividad con respecto a formas de subjetividad anteriores? ¿De qué modos están incidiendo en la transformación de las propuestas literarias surgidas en los últimos años? Esta serie de preguntas despierta, a su vez, otras preguntas de una naturaleza distinta, como por ejemplo, ¿qué relación se establece entre las estructuras y dinámicas instauradas por el capitalismo en su fase actual y las nuevas formas de creatividad?, o ¿cómo articula el propio sistema estas nuevas formas de creatividad, en el caso de la literatura?, y ¿cuáles son las dinámicas que el mercado editorial establece entre ideología, creatividad y canon?

\footnotetext{
${ }^{2}$ El punto de partida de esta reflexión en torno al estado de la cultura española, está en el concepto "Cultura de la Transición", acuñado por el periodista Guillem Martínez y surgido en la prensa al calor de las protestas del 15M. Es interesante, en este sentido, la lectura de una compilación de ensayos titulada CT o la Cultura de la Transición (Mondadori, 2012) y coordinada por Martínez, en la que participan varios autores y que fue publicada a raíz del primer aniversario del movimiento 15M. En estos ensayos se propone el concepto $C T$ para poner en duda la construcción de un modelo cultural basado en la idea del consenso, y que en los últimos tiempos se ha evidenciado como un pensamiento oficial y dirigido que ha condicionado enormemente el desarrollo de la producción cultural en la España contemporánea.
} 
En el marco de la narrativa española contemporánea, la respuesta a estas preguntas levanta algunas sospechas con respecto a la configuración de un canon literario que, hoy por hoy, no parece lo suficientemente permeable a buena parte de las novedosas propuestas literarias que han ido surgiendo con una intensidad creciente desde el cambio de siglo. De este modo, en nuestro panorama literario el décalage entre la realidad y la narrativa española parece manifestarse, fundamentalmente, en dos niveles. El primero, en el plano de la forma, donde la indiscutible presencia de la tecnología y de los medios de comunicación como condicionante en la producción literaria contemporánea no parece haber sido tomada demasiado en serio por la crítica literaria. Tanto es así que buena parte de las propuestas narrativas que vienen de autores relativamente jóvenes y que dan cuenta del significativo cambio en la relación entre sujeto y realidad como consecuencia de la influencia de los medios tecnológicos han quedado hasta el momento alejadas de los circuitos editoriales más visibles. El segundo nivel está en el plano del contenido, ya que nuestra cultura narrativa oficial parece estar enunciada, como decíamos más arriba, desde cierta postura autocomplaciente con respecto a la Historia más reciente. Una autocomplacencia que permite escribir novelas metaficcionales, sobre la Guerra Civil y sobre la Transición, pero desvía constantemente la mirada de las problemáticas de nuestro presente. ${ }^{3}$ Es precisamente como reacción frente a esta autocomplacencia y frente a este ensimismamiento estético, que parece haber surgido la propuesta literaria que aquí nos proponemos presentar y discutir.

\section{La propuesta Nocilla. "Puedes llamarlo Nocilla o como te dé la gana"4}

Al margen del consenso estético que se exhibe en los estantes de las grandes librerías del país, desde hace unos años se viene gestando una propuesta narrativa que llama la atención por su dimensión sintomática del momento en que se produce. Es importante destacar que este consenso estético, sostenido en buena medida por la fuerte presencia de

\footnotetext{
${ }^{3}$ Ya en 2009, Claudio Cifuentes analizaba, en un texto titulado "La a-historicidad de la novela del fragmento: de Rayuela a Nocilla Dream" (Cifuentes Aldunate, 2012), la aparición de una novela ahistórica o contra-novela que retomaba en cierto modo la tradición de la literatura experimental de finales de los sesenta y principios de los setenta. En este texto, se aludía a través del análisis comparativo de ambas novelas, a la manifestación en la narrativa española de una corriente ahistórica, experimental, como el reverso de la profusión de novelas de corte realista sobre la memoria surgida en nuestro entorno narrativo en la última década.

4 Así arranca una de las reseñas más contundentes de las múltiples en las que la prensa recoge, amplía y difunde el "fenómeno Nocilla": "Puedes llamarlo Nocilla o como te dé la gana. Puedes ponerle todas las etiquetas que necesites para entender que el fantasma de la literatura se ha levantado, y que ha regresado por puro hartazgo para imponerse al mercado y a las ventas" (Riaño, 2008).
} 
los grandes popes de la narrativa española del periodo democrático como Cercas, Marías, Millás o Vila Matas, etc. - debido, entre otras cosas, a su enorme rentabilidad editorial dentro y fuera del país-, es cada vez más puesto en entredicho por la presencia mediática creciente de autores de generaciones posteriores con interesantísimas propuestas narrativas (Isaac Rosa, Belén Gopegui, Antonio Orejudo, Rafael Reig, etc.). Es significativo el cambio en la naturaleza de los medios a través de los que los que estos últimos se presentan -y representan - socialmente, ya que el blog parece haber sustituido al suplemento literario y la contraportada de El País parece haber sido sustituida por una columna en publico.es o eldiario.es. Aunque este último no sea el caso de los autores que integran la generación Nocilla - que nos conste, al menos todavía no ejercen de columnistas en ningún periódico - la propuesta literaria más o menos cohesionada entre estos autores nos interesa por su dimensión sintomática. Hablamos de una dimensión sintomática porque sus planteamientos estéticos se relacionan directamente con el presente tecnológico del que surgen y su ideología pretende trascender los planteamientos políticos a los que nuestra narrativa nos tiene acostumbrados.

Si bien la transcendencia del planteamiento generacional con el que se presentó esta línea narrativa ya está en buena parte superado, nos detendremos aquí a analizar la propuesta narrativa llevada a cabo por este grupo de autores como una primera manifestación narrativa sintomática y como una declaración de principios de lo que, sin duda alguna, empieza a convertirse en una importante tendencia en el contexto de la narrativa española actual pero que, al mismo tiempo, guarda paralelismos significativos con otras narrativas surgidas en el marco global ${ }^{5}$. Esta propuesta consiste fundamentalmente en la elaboración de una literatura que tiende a la espectacularización autoconsciente de las consecuencias estéticas e ideológicas de las transformaciones ocurridas en las formas de producción cultural de los últimos tiempos, y que pasan, en gran medida, por la enorme influencia de las tecnologías y los medios de comunicación sobre los modos de representación literaria. Esta propuesta ha acabado por convertirse en uno de los modelos literarios más viables de la última década y ha abierto la puerta a un modelo narrativo que evidencia una profunda transformación ideológica con respecto a modelos narrativos

\footnotetext{
${ }^{5}$ Nos referimos a planteamientos similares surgidos en otros ámbitos hispánicos como es el caso del precedente que supuso la antología de relatos McOndo (Mondador, 1996) en Chile y Argentina, que generó la llamada generación McOndo, en la que Alberto Fuguet y Rodrigo Fresán estuvieron implicados, o, en México, la publicación en la editorial Almadía de otra antología de naturaleza similar, titulada Grandes hits. Nueva generación de narradores mexicanos (Almadía, 2008). El surgimiento de este tipo de iniciativas en el marco de las diferentes narrativas hispánicas dan cuenta de que el análisis que nos proponemos se inserta en la lógica de una tendencia que se da más allá de nuestro contexto nacional, y nos lleva, de algún modo, a reafirmarnos en nuestra propuesta de análisis.
} 
anteriores. Se han usado distintas etiquetas para referirse a esta propuesta, pero en su momento cuajó una: la generación Nocilla.

Conocemos por generación Nocilla a un grupo de autores españoles que, pese a la heterogeneidad existente entre sus obras y perfiles, reivindica de forma explícita un modelo de literatura realizado bajo la influencia de los medios tecnológicos de la información. Se trata este nombre de una etiqueta cuya vinculación con lo comercial obtura el alcance y las implicaciones reales de la propuesta. En primer lugar, la idea de generación —muy trillada como estrategia editorial - neutraliza lo que en realidad podría o debería entenderse como la expresión de un malestar, de una inconformidad, con las formas literarias imperantes por parte de un grupo de autores que, por una cuestión de edad, plantean el reconocimiento del salto que se ha producido entre su imaginario generacional y el imaginario cultural imperante, que es el que se proponen asaltar: "Dos órdenes de poder, por tanto: una jerarquía generacional que se hace coincidir con una jerarquía cultural. Este doble orden es uno de los factores que garantizan la estabilidad del sistema de las letras, en nuestro país como en otros" (Fernández Porta, 2007: 24).

No obstante, resulta del todo evidente cuánto hay de operación de mercado en el esfuerzo por legitimar un producto que aspira a competir por el consumo literario mediante la etiqueta de "generación". Esta operación se ha repetido con mayor o menor éxito en el marco de la literatura con los Novísimos, la Generación X o los Poetas de la Experiencia. Dicho esto, en el caso de los Nocilla el humor parece haber sido un fuerte elemento cohesionador. La idea de un sentido del humor común pasa por el hecho de compartir una visión de mundo determinada y, con frecuencia, de carácter más o menos generacional. Es ahí donde reside, en nuestra opinión, un potencial crítico que ha cristalizado, en este caso, en el surgimiento de un grupo de autores, todos nacidos alrededor de los años setenta, y que se presentan con algo parecido a un programa o un imaginario común, surgido de un cambio cultural e histórico: el salto hacia la Era de la Información. Es de este modo que la cuestión generacional se articula al margen del mercado, pero finalmente acaba siendo aprovechada y apropiada por los mecanismos de mercantilización del negocio editorial.

El apellido Nocilla, fue tomado por la prensa literaria de la trilogía de Fernández Mallo titulada Proyecto Nocilla y compuesta por las novelas Nocilla Dream (Candaya, 2006), Nocilla Experience (Alfaguara, 2008) y Nocilla Lab (Alfaguara 2009). El conjunto de estas tres novelas es considerado por los propios autores como el texto programático de esta nueva generación; una generación fundamentalmente de narradores. La etiqueta "generación Nocilla" ha sido y es conflictiva, porque imprime en esta propuesta cierto tono superficial en el que algunos de los autores implicados no se reconocen. Las discusiones en torno al nombre han desatado múltiples y encendidos debates que han tenido lugar principalmente en los blogs, en alguna entrevista, en artículos de opinión en revistas 
específicas o en algún suplemento literario. Al margen de "Nocilla"6 , se han propuesto otros nombres para la generación, como es el caso de "Mutante" - a raíz de la antología de cuentos titulada Mutante. Narrativa española de última generación (Berenice, 2007) - o "Afterpop" - por el ensayo de Eloy Fernández Porta Afterpop. Literatura de la implosión mediática (Berenice, 2007), clave en la conformación de esa tendencia.

La idea de la generación Nocilla como fenómeno editorial surge de los propios medios de comunicación para nombrar - y al nombrar, marcar- un fenómeno que tanto tiene de literario como de mediático. En este sentido, es cierto que la transformación de esta propuesta literaria en artefacto de mercado le debe mucho a la prensa, ya que la novedad del planteamiento literario del mismo viene acompañada por un despliegue mediático y comercial que ha contribuido enormemente a la formación de un imaginario Nocilla. No obstante, este imaginario Nocilla constituye hoy, más de diez años después de que empezaran a surgir los primeros libros de algunos de estos autores como verdaderas excentricidades editoriales, una línea de producción literaria contemporánea totalmente reconocible y en torno a la cual parecen polarizarse las posiciones críticas. No obstante, no debe olvidarse que esta etiqueta comercial surge fundamentalmente de un lenguaje de suplemento cultural que tiende a esclerotizar cualquier signo de creatividad emergente. Lo importante aquí, en definitiva, es destacar el surgimiento de un grupo autoconsciente de jóvenes autores, establecido a través de un vínculo generacional y cultural que ha catalizado en la producción de una literatura específica, realizada desde una perspectiva novedosa:

Esa conciencia tecnológica es realmente nueva, diferencia nuestro momento histórico de los precedentes. También es nuevo el posicionamiento respecto a la política, que ha superado la dicotomía de los partidos de izquierda o de derecha [...]. Obviamente, por haber vivido la juventud en la misma época, compartimos un horizonte televisivo, iconos pop, una cierta forma de vivir la sentimentalidad, la frecuentación de países e idiomas, una formación académica interdisciplinar, etc. De eso se habla continuamente en los blogs, las tertulias y espacios de encuentro más importantes de nuestro presente (Calvo, 2007). ${ }^{7}$

\section{Circunstancias de aparición y formas de autopresentación de la generación Nocilla.}

"La realidad ya no es lo que era, porque se puede modificar, mutar, transformar y agredir. Las nuevas tecnologías han logrado incrementar el poder de la palabra" (Riaño, 2008). Dicho esto, empecemos por el principio. La generación Nocilla empezó a

\footnotetext{
${ }^{6}$ En el origen del nombre de la trilogía sí hay un guiño generacional. Según el propio Mallo, es la canción "Nocilla, qué merendilla" (1983), del grupo de punk español Siniestro Total.

${ }^{7} \mathrm{El}$ autor de este artículo es Javier Calvo, pero el que dice estas palabras es Jorge Carrión, ambos vinculados a la generación Nocilla.
} 
visibilizarse como tal en el año 2007, tras la celebración del primer encuentro de nuevos narradores "Atlas Literario Español", organizado por la editorial Seix-Barral y la Fundación José Manuel Lara, celebrado en Sevilla del 26 al 28 de junio de 2007. A raíz de este encuentro, la prensa empezó a hablar de la generación Nocilla como una entidad en la literatura española contemporánea escrita por jóvenes pero todavía sin demasiada visibilidad en los circuitos literarios más convencionales. Obviamente, el interés de la prensa se debía al hecho de que la aparición de un grupo de autores que empezaba a presentar una serie de propuestas narrativas que plateaban una problemática más o menos común era susceptible a convertirse en un producto editorial muy rentable. ${ }^{8}$ De forma inmediata, se desencadenó en periódicos y suplementos culturales una potente campaña de difusión. De hecho, fueron dos periodistas - Nuria Azancot, redactora del suplemento El Culural, y Elena Hevia, de El Periódico- quienes empezaron a formular la idea de la generación Nocilla de forma más visible, así como a exponer de forma más o menos contundente - pero sin demasiado rigor crítico- las supuestas premisas en las que se basaba la escritura de los Nocilla.

La nómina de escritores que, por algún motivo o por otro, han sido adscritos a la generación Nocilla es amplia, abierta, inestable y variada. Podríamos dar una relación de nombres, pero, siendo sinceros, no tendría el más mínimo rigor. Sí que hay tres que están en la base de la construcción de este proyecto literario más allá de esa voluntad de la prensa por dar una solidez totalmente aparente a algo que, en absoluto la tiene. Si bien podemos hablar de Agustín Fernández Mallo, Eloy Fernández Porta y Vicente Luis Mora como los ideólogos del proyecto literario del que estamos hablando, no parece pertinente promover desde aquí la ficción de la existencia de un grupúsculo literario cerrado. Lo interesante de este proyecto -explicado, además, en un video titulado Proyecto Nocilla. La película que puede consultarse en el blog personal de Agustín Fernández Mallo "El hombre que salió de la tarta", en el que podemos escuchar a estos tres autores explicar en qué consiste este proyecto- es que funciona como una especie de plataforma que, casi de forma accidental, irá aglutinando a su alrededor una serie de nombres que se identificarán más o menos con las premisas que estos autores plantean en relación a lo literario. Los nombres que, en este sentido, aparecen con más frecuencia son, por ejemplo, los de Manuel Vilas, Javier Calvo, Jorge Carrión, Juan Francisco Ferré, Germán Sierra, Robert Juan Cantavella, Mercedes Cebrián, Diego Doncel, Lolita Bosch, entre algunos otros. Más allá de su vinculación declarada, o no, con la generación Nocilla, Mutante o Afterpop, comparte la producción de

${ }^{8}$ Sobre la rentabilidad de la etiqueta "Nocilla", es muy significativo el hecho de que la primera novela del "Proyecto Nocilla" de Agustín Fernández Mallo -de la que hablaremos más adelantefuera publicada en 2006 por Candaya, una editorial minoritaria, indie, mientras que la segunda y la tercera parte fueran publicadas por la editorial Alfaguara, una de las más potentes y comerciales del ámbito editorial español, perteneciente al grupo PRISA. 
estos autores ciertos rasgos que son producto de la voluntad de reflejar la transformación que los medios tecnológicos han ejercido sobre su forma de entender la literatura.

Dado que es esa influencia tecnológica sobre las formas del narrar el lugar desde el que se reivindican estos autores, resulta interesante detenerse a observar qué modos y qué canales han escogido para autopresentarse $-\mathrm{y}$ autorrepresentarse- como narradores, como críticos culturales, o incluso como personajes mediáticos. En este sentido, tras llevar a cabo un rastreo más o menos riguroso en la red, uno llega a la conclusión de que es fundamentalmente el blog personal lo que a estos autores les sirve de tribuna para difundir, no solamente las novedades que van publicando, o pequeñas dosis de ejercicios más o menos literarios, sino algo tal vez todavía más importante por las repercusiones que, a la larga, está empezando a tener en la reconfiguración de un canon literario cada vez más supeditado a los intereses de un mercado editorial en dificultades. Hablamos de la difusión e importancia que los propios autores dan a sus opiniones y gustos literarios, es decir, la difusión de las pasiones y odios tanto profesionales como estéticos en el campo de la narrativa nacional, de los gustos literarios de otros ámbitos nacionales, etc. De este modo, desde el blog, los autores que se lo proponen ejercen, además de escritores, de críticos literarios y, de paso, se permiten defenderse y contestar a otras críticas. Esta forma de difusión de la propia escritura y de crítica de la ajena, supone un importante cambio de perspectiva con respecto a las dinámicas tradicionales, en las que los periódicos, revistas y suplementos culturales eran, junto con los medios académicos, el espacio desde el que la crítica era un ejercicio unidireccional, cuando los que escribían eran los escritores y los que juzgaban eran los críticos.

No obstante, también han surgido de la propuesta Nocilla otras formas de presentación más allá de lo estrictamente literario, que algunos de estos autores han empleado para transgredir la tradición. Es el caso de la realización de una serie de performances llevada a cabo de forma periódica por Agustín Fernández Mallo y Eloy Fernandez Porta, titulada Afterpop: Fernández \& Fernández. Esta serie de representaciones se plantean como una forma alternativa de difusión para los textos de ambos autores y consiste, básicamente, en la puesta en escena de la "Teoría del afterpop" (Fernández Porta, 2006). Se trata de un spoken word, esto es, un tipo de espectáculo, a medio camino entre el recital y el monólogo rapeado, en el que ambos autores llevan a escena algunas reflexiones y conceptos que ellos mismos han teorizado en sus obras ${ }^{9}$. La elección de este formato como un modo de autopresentación puede ser interpretada como la búsqueda de una manera

9 Tampoco debemos olvidar que algunas de las obras de estos autores, que sirven como núcleo para el spoken word, han sido premiados con prestigiosos galardones. Los casos más destacados son el del ensayo de Eloy Fernández Porta titulado Eros. La superproducción de los afectos, que fue Premio Anagrama de Ensayo en el año 2010, o el de Agustín Fernández Mallo, titulado Postpoesía. Hacia un nuevo paradigma, que fue finalista del premio Anagrama de ensayo en 2009. 
inmediata y directa de condensar en breves escenas, en eslóganes conceptuales y, en definitiva, en formatos fáciles de digerir, teorías más o menos complejas para un público más amplio que el que normalmente lee ensayo de forma asidua. Además, los contextos en los que se suele representar esta serie Afterpop han ido, en ocasiones, mucho más allá de los espacios puramente mediáticos o artísticos como televisiones, encuentros de creación o museos, y han llegado a representarse en espacios exclusivamente académicos, como fue el caso de la intervención en la conferencia de Estudios Transatláticos llevada a cabo en la Unversidad de Brown en abril de $2012^{10}$.

Más allá del recurso a estas fórmulas novedosas, tal vez el instrumento más potente -y también el más tradicional- con el que los autores afines a la generación Nocilla cuentan para la difusión pública de su literatura es, sin duda, la revista literaria Quimera. Al margen de otras publicaciones a través de las cuales también se ha difundido la obra de estos autores, y en las que ellos mismos han escrito frecuentemente - revistas como Qué leer o Lateral-, el papel protagónico de la revista Quimera en el lanzamiento, crítica y difusión de la ficción Nocilla ha sido, y sigue siendo, indiscutible.

Fundada en 1980 y siempre dando cuenta de la vanguardia literaria en España, la revista Quimera cambia notablemente su rumbo a partir de 2006, año en que Fernando Valls deja la dirección de la revista y es sustituido por una comisión formada por Jorge Carrión, Jaime Rodríguez Závala y Juan Trejo, que finalmente será retomada únicamente por Jaime Rodríguez Závala en 2009 y hasta la actualidad. La explosión del fenómeno Nocilla coincide con el momento en que esta comisión se pone al frente de la revista y desde el principio se consolida como medio de difusión de este tipo de novedades literarias en el panorama español. No obstante, da la sensación de que es a partir de 2009, el año en que Jaime Rodríguez Závala pasa a ser el director, cuando la presencia de las voces que conforman este grupo se intensifica, de manera que gran parte de los últimos números están plagados de artículos, entrevistas y reseñas de autores como Vicente Luis Mora, Eloy Fernández Porta, Agustín Fernández Mallo, Jorge Carrión, Javier Calvo, Rodrigo Fresán, etc.

La profusión de artículos de y sobre los autores de la generación Nocilla en Quimera ha contribuido de forma decisiva a la conformación de una imagen cada vez más madura de sí mismos como un grupo joven y competente para incidir de modo significativo en el panorama narrativo español actual. No obstante, la importancia del papel de la revista Quimera en la adquisición no únicamente de difusión, sino también $-\mathrm{y}$ tal vez sobre

${ }^{10}$ Este congreso se lleva a cabo cada dos años desde el Departamento de Estudios Hispánicos de la Universidad de Brown. El programa de la edición de 2012, en el que figura la intervención de Eloy Fernández Porta y Agustín Fernández Mallo puede consultarse en: http://www.brown.edu/Departments/Hispanic_Studies/transatlantic_project/documents/6thIntern ationConferenceonTransatlanticStudiesProgram.pdf 
todo- de prestigio y visibilidad en el panorama literario contemporáneo nos lleva a una conclusión que debe ser tenida en cuenta a la hora en abordar el estudio crítico de la generación Nocilla. Y es que, al margen de las innovaciones propuestas con respecto a las formas y canales de la crítica tradicional, todo parece apuntar al hecho de que el papel sigue siendo el depositario del máximo prestigio, ya que al fin y al cabo es en él donde estos autores están buscando el reconocimiento, donde la crítica tradicional - esos críticos reconocidos por la Academia, como Pozuelo-Yvancos. Anna Caballé o Jordi Gracia ${ }^{11}$ empieza a ocuparse de ellos.

También es fundamental el papel colaborador de ciertas editoriales minoritarias que funcionaron durante los primeros años como distribuidoras y órganos de difusión. Hablamos de editoriales como Berenice, DVD y Plurabelle. Es destacable, como ya se ha comentado más arriba, el hecho de que los autores más emblemáticos hayan acabado trabajando con editoriales que se rigen en buena medida por índices de rentabilidad como es el caso de Alfaguara, que ha publicado las dos últimas partes del Proyecto Nocilla - o con editoriales de más prestigio - como Anagrama-. En este recorrido, que va de lo indie, de lo alternativo, a la inserción de la propuesta del fenómeno Nocilla en la lógica comercial del mundo editorial español y su consolidación como producto de consumo, está cifrada la voluntad real de inserción en el canon y de visibilización mediática de esta propuesta. Este hecho abriría un camino para la interpretación del fenómeno ya no como una propuesta literaria consistente o innovadora, ni tampoco como un movimiento contracultural al uso - como fue el caso en las décadas de los sesenta y los setenta con la cultura hippie o de los ochenta y los noventa con el punk y el grunge- sino como una propuesta que busca desestabilizar el modelo literario oficial con el objetivo último de entrar a formar parte de él.

\section{El precedente: Proyecto Nocilla, Agustín Fernández Mallo (2006-2009)}

Resulta pertinente, llegados a este punto, hacer referencia a esos tres textos que integran el Proyecto Nocilla que Agustín Fernández Mallo publicó entre los años 2006 y 2009, y que parecen haber desencadenado en el plano de la narrativa la reflexión que está en la base de la propuesta de la generación Nocilla. De la aparición del primero de estos textos, sin ir más lejos, tomó la prensa el nombre que acabó cristalizando en el membrete bajo el que acabarían incluyéndose muchos otros autores.

Un buen fragmento como punto de partida para exponer la naturaleza del Proyecto Nocilla sería el siguiente:

11 Para más información, resulta muy interesante consultar el número 313 de la revista Quimera, donde hay un puede leerse "Dossier: Novela Española 2000-2009" en el que se incluyen las reflexiones de estos críticos, entre otras. 
El nuevo capitalismo, el del siglo 21, no solo ofrece productos de consumo para sentir a través de ellos un estatus o una ensoñación, eso está ya superado, lo que hace es crear una auténtica realidad paralela que se erige en única a través de los medios de comunicación. Así que más que nunca la común Realidad imita lo artificial, al Arte. Ahora bien, ese arte, que ya es la nueva Realidad, agobia por lo excesivamente estándar, por eso los chinos hace tiempo que copian todo lo Occidental pero introduciéndole ciertas transformaciones; lo customizan (Fernández Mallo, 2006: 159).

En relación con las reflexiones con las que abríamos este artículo, es desde esta alusión al nuevo capitalismo del siglo XXI desde la que el Proyecto Nocilla cobra un sentido de síntoma, de muestra del efecto que una nueva realidad artificial, una auténtica realidad paralela tiene sobre la literatura, y que como tal debería ser tratado por la crítica. Del mismo modo que los chinos copian y customizan todo lo occidental, el Proyecto Nocilla se apropia y recicla el bagaje literario, científico, cultural e histórico de los últimos tiempos, y lo convierte en una nueva forma de discurso narrativo, sintético y antinatural. A pesar de su tono, por momentos ciertamente algo pretencioso y tal vez no tan original como se pretende a sí mismo, las tres novelas que conforman este proyecto suponen un notable desmarque con respecto a otras formas de literatura que se viene produciendo en los últimos años.

Es cierto que, en ocasiones, la reivindicación de lo frívolo, de lo vacío, de lo artificial pone a un lector politizado en una posición ideológica incómoda, ya que en esta serie de narraciones, lo que parece implícito es una especie de apología de las formas vacías de representar surgidas de ese nuevo capitalismo. No obstante, el gesto crítico que aquí proponemos para la lectura de las formas narrativas inauguradas por el Proyecto Nocilla es el de la reflexión en torno a los posibles significados que el desarrollo de estas formas apologéticamente superficiales y fragmentarias cobra en el contexto actual, y sobre el potencial que a este respecto tienen algunas de las metáforas planteadas a lo largo de los tres ejercicios narrativos de la Nocilla.

Los tres libros que conforman el Proyecto Nocilla (Nocilla Dream, Nocilla Experience y Nocilla Lab) suponen, cada uno a su manera, la reivindicación de una nueva sensibilidad marcada por los efectos de las nuevas tecnologías de la comunicación y de una escritura llevada a cabo bajo la exposición constante, ininterrumpida, de las más diversas formas de la información.

\subsection{Nocilla Dream (Candaya, 2006)}

En varias entrevistas en las que se le ha preguntado a Fernández Mallo sobre el porqué del nombre de su trilogía, su respuesta ha sido que la idea de la primera novela se le ocurrió mientras escuchaba la canción de Siniestro Total "Nocilla, qué merendilla" y, al 
mismo tiempo leía una noticia titulada "Un árbol de zapatos crece en una solitaria ruta del desierto" en el suplemento New York Times que solía aparecer en El País los jueves ${ }^{12}$.

La primera de las novelas de la trilogía es, a efectos prácticos, una presentación del imaginario Nocilla que irá siendo, si no completado - puesto que hablamos de algo que es, por definición, fragmentario, asimétrico e incompleto-, sí esbozado de una forma característica, como en una especie de microcosmos pixelado.

Nocilla Dream consiste en una narración armada a través de la compilación de 113 fragmentos de distinta naturaleza y de distintos autores -además del propio Fernández Mallo- y con contenidos aparentemente dispares pero remotamente relacionados entre sí. Lo que se narra es algo que se parece a una historia, pero no tiene ni principio ni fin determinados.

En mitad del desierto de Nevada, por donde pasa la carretera más solitaria de Norteamérica - la US50 - , hay un álamo centenario del que cuelgan miles de pares de zapatos. Zapatos de tacón, italianos, chilenos, deportivas de todas las marcas y colores (incluso unas míticas Adidas Surf), aletas de buceo, botas de esquí, botitas de niño o botines de charol. Cada uno de esos pares de zapatos tiene una historia detrás, y algunas de esas historias se intercalan entre los fragmentos que componen la novela.

Historias como la del ex boxeador Falconetti, que con sus zapatillas Nike y una pequeña mochila decide recorrer estados unidos de Este a Oeste - al contrario que Cristóbal Colón, dice - y justo cuando llega al olmo lanza sus desgastadas zapatillas al árbol y las cambia por unas botas militares, con las que sigue su camino. O como la de Sherry, una prostituta que vive en medio de ese mismo desierto, y cuya propia vida es, en sí, un desierto, un páramo que de repente un hombre llamado Pat Garret decide atravesar, aunque sea únicamente para una noche, para irse a toda prisa a la mañana siguiente, por esa carretera US50, y nunca más volverla a ver. O la historia de Hannah y Ted, y de cómo se conocieron a través de un libro de poesía experimental escrito por Hannah y encontrado de forma totalmente azarosa por Ted sobre una silla en una área de servicio de Utah, y acaban formando una familia e instalándose en una de las miles de micronaciones que existen en el mundo hoy en día. Y así, una detrás de otra o entrelazándose entre sí, se van sucediendo pequeñas historias que no tienen más trascendencia de la que conforman todas como conjunto, como marco estético en el que insertan una serie de reflexiones científicas, tecnológicas, artísticas y literarias que conforman ese el universo Nocilla.

Italo Calvino, Borges, Thomas Bernhard, Wiliam Blake, Juan Benet, Guy Debord, Radiohead, Los Surfin' Bichos... En la medida en que avanza la novela los nombres propios se van sucediendo y entremezclando con altisonantes etiquetas teóricas muy específicas de

\footnotetext{
12 Esta noticia, debidamente reseñada en el apartado "Bibliografía citada", puede encontrarse en una versión online en la siguiente dirección: http://alca-seltzer.org/elpais/20040610.pdf
} 
diferentes ámbitos del saber, como "La Teoría de la Deriva", "Principio de Reversibilidad universal", "La muerte del autor", etc. Y todo esto se entremezcla con alusiones al Gran Hermano, la reproducción del pasaje de un texto de Ernesto Sábato sobre Jorge Luis Borges o la reflexión de un niño en torno a una foto tomada en Hiroshima poco después de la caída de la bomba atómica en la que aparece un hombre con un paraguas.

La cohesión entre la aparente disparidad de los fragmentos que constituyen este artefacto como una entidad narrativa, viene dada por la recurrencia y la reformulación de una serie de metáforas y reflexiones que giran en torno a la idea del Desierto, del Páramo; de la planicie inmensa y polvorienta que queda sugerida al lector a través de la recurrencia de la imagen del desierto de Nevada y la alusión esporádica a otro desierto más local: la Mancha, ese desierto remotamente cercano/local situado entre "los estados de Albacete y Almería".

Además de a un lugar físico, el Desierto remite, en ese imaginario Nocilla, a una serie de lugares comunes en la sociedad digital; lugares en un sentido tanto material como inmaterial, tanto literal como metafórico:

Tarde o temprano nuestras costas quedarán vacías. Cientos de kilómetros de cemento permanecerán durante siglos cayéndose a pedazos y cubriéndose de zarzamora y ortiga. Por la noche sonarán en su interior aullidos insoportables. Zonas inmensas de este país se convertirán en refugio de criminales, plantas de fabricación pirata, cuarteles de mafias orientales, talleres textiles ilegales, clubes de rufianes eslavos. La ruina y el espanto extenderán su sombra amarilla sobre unos lugares en donde tiempo atrás, como en el Líbano, giraban las ruletas más caras del planeta mientras delgadas actrices apenas adolescentes sorbían láudano en compañía de futuros suicidas. (Félix de Azúa) (Fernández Mallo, 2006: 101).

Ese desierto, ese páramo físico y geográfico tiene su correlato subjetivo en la construcción de los personajes que van apareciendo en esta primera parte del proyecto. En esta primera novela la atención narrativa se concentra en el armazón paisajístico e imaginario de ese mundo Nocilla como paisaje mediático ${ }^{13}$, en la idea del desierto como metáfora de la sociedad postcapitalista. En las dos novelas siguientes ese punto central de la constitución de una metáfora visual se irá desplazando hasta llegar a focalizar esa la idea del páramo en ciertas formas de subjetividad, siempre proyectadas sobre la metáfora de fondo del árbol en medio del desierto del que cuelgan centenares de zapatos de todo tipo; como una especie de representación visual del estado subjetivo en el que se encuentra el

${ }^{13}$ El concepto paisaje mediático es propuesto por Eloy Fernández Porta en Afterpop. La literatura de la implosión mediática para referirse al conjunto de iconos y representaciones tecnológicamente producidas que constituyen la esfera del consumo y la información, de contenido fundamentalmente visual y que percibimos como naturaleza en segundo grado (Fernández Porta, 2007: 67). 
individuo en la Era Digital. La fascinación por esa imagen del desierto funciona como eje en torno al cual se articulan una serie de reflexiones en torno a la nada; en torno a la nada en sus múltiples sentidos, quedando fijada de forma simbólica. En el centro de esta imagen, el vacío: las palabras que, al repetirse, dicen sin decir nada, por el mero hecho de haber sido dichas por alguien en un momento dado y, a fuerza de repetición, han sido introducidas en la lógica del sistema cultural.

En la sucesión de fragmentos escogidos viene cifrado un perfecto ejemplo -el primero de los tres que brinda a la crítica la trilogía Nocilla- de ese movimiento centrípeto experimentado por la literatura como discurso en el contexto de la sociedad de la información, y a la que Fernández Porta se refirió poco después de la publicación de Nocilla Dream como "literatura de la implosión mediática" ${ }^{14}$. La sobresaturación de información, la relatividad de las fronteras físicas - micronaciones, no lugares; aeropuertos, supermercados - y de los afectos, cristalizan en una irónica frivolidad, o en una frivolidad irónica - según el momento- no siempre fácil de encajar para un lector no demasiado familiarizado con un sentido del humor peligrosamente cínico y tremendamente irrespetuoso con los posicionamientos e iconos políticos tradicionales, heredados del siglo $\mathrm{XX}$. Este hecho es uno de los aspectos más contundentes a la hora de sostener el interés crítico sobre el Proyecto Nocilla, y de interpretarlo como una nueva tendencia narrativa que, de forma oblicua, permitiría tratar los aspectos más relevantes en la reflexión en torno a los efectos de la Era de la Comunicación en la transformación de la narrativa.

Lo que nos queda claro en esta primera parte es que estamos ante un autor que puede reírse de ciertas cosas de las que no es fácil burlarse desde posturas éticas y políticas más definidas; un autor cuya postura parece ser extensible a otros autores generacionalmente relacionados con Fernández Mallo ${ }^{15}$, que son capaces de frivolizar en torno a temas políticos y sociales de un modo claramente vanguardista.

\subsection{Nocilla Experience(Alfaguara, 2008)}

La segunda parte de este proyecto, bajo el título de Nocilla Experience parece tener la intención de relatar, siempre recurriendo a esa particular forma de fragmentar la narración, diversas experiencias Nocilla. Siguiendo una estructura similar a la de la primera parte, consistente en el intercalado de textos de diversa naturaleza y procedentes de diversos medios, el gesto de esta segunda novela de la trilogía Nocilla se va afinando, y de la construcción en abstracto de ese imaginario tan concreto atravesado por la imagen del

\footnotetext{
${ }^{14}$ Fernández Porta (2007).

15 En este sentido, es interesante también la lectura de otras novelas que se sitúan en posicionamientos estéticos e ideológicos similares, como por ejemplo la novela España (DVD, 2008) de Manuel Vilas, entre otros.
} 
desierto de Nevada y el árbol de zapatos, la narración se desliza hacia la construcción de una serie de personajes o de situaciones marcadas por la peculiaridad. Al margen de crear personajes más o menos problemáticos -los hay, problemáticos, pero también los hay extraordinariamente comunes - lo que parece interesarle a Fernández Mallo es destacar las peculiaridades, los elementos más fuera de lo común dentro de lo común de los elementos que caracterizan a cualquier persona.

A través de una estética que, aunque tal vez menos edulcorada, converge en ciertos aspectos con aquel imaginario de lo común maravilloso creado con enorme éxito por el cineasta francés Jean-Pierre Jeunet en su película Amélie (2001), en Nocilla Experience parece que subyace un intento de hacer extensible un mundo Nocilla a todos nosotros. Lo único que hay hacer para entrar en él es poner una lupa sobre aquellas pequeñas cosas que nos individualizan -aunque sea de forma muy superficial- de un colectivo homogeneizado, en la búsqueda de una especie de oxímoron estético, algo así como una "extravagancia convencional", con pleno sentido en el contexto de lo que algunos llaman, medio en broma, la Era Facebook.

Directamente en relación con la cuestión de la identidad, la imagen del desierto, del páramo que articulaba la primera parte queda sustituida por la vuelta constante a ese Palacio de Cristal. Se trata de un enorme y lujosísimo palacio situado en otro páramo: la estepa Rusa, y que alberga en su interior un Museo del Parchís. El parchís como juego de azar; el parchís, en su irracionalidad, como oposición a la mecánica racional del ajedrez, que parece ser la metáfora tradicional de la vida. La imagen de la vida como tablero de ajedrez pasa a ser, en el universo Nocilla, la vida como tablero de parchís: "El mundo se rige por el azar de un parchís, no por las mecánicas leyes del ajedrez".

Esta idea del azar, nuclear en la construcción de los vínculos cuidadosamente establecidos entre las historias de los personajes que componen esta segunda parte, también estará fuertemente presente la tercera parte de la trilogía, Nocilla Lab, a través de la recurrente alusión a la novela de Paul Auster La música del azar, que da al lector una importante clave de lectura. Precisamente sobre la cuestión del azar se proyecta una cuestión nuclear en la novela: la fascinación por la complejidad y la arbitrariedad de las relaciones humanas. En este sentido, las vidas de los diversos personajes que van apareciendo en la novela - Sandra, Marc, Jota, Antón y Josecho- están cuidadosamente vinculadas entre ellas a través de conexiones totalmente azarosas. De ahí la exposición de la Teoría de las Bolas abiertas de un señor llamado Julio Cortázar, que ha escrito un libro llamado Rayuela y Rayuela $B$ para exponer su hipótesis científica sobre la complejidad de las relaciones interpersonales.

Sobre este fondo, el intercalado de algunos episodios muy fragmentarios, de historias muy diferentes entre sí pero que, de algún modo - y como ocurría en Nocilla 
Dream—, acaban estando relacionadas las unas con las otras, junto con la reproducción literal de fragmentos de revistas científicas específicas de ciencia y tecnología, entrevistas a músicos pop, reportajes, digresiones filosóficas y recortes de prensa tomadas de diversos medios y autores - pero siempre reproducidas bajo el nombre de quien lo escribióconforman, de nuevo, un ente narrativo que ni empieza ni acaba. Los fragmentos narrados en forma de historia están plagados de nombres de escritores, grupos de música, pintores, cuya enumeración casi acumulativa deja entrever una voluntad de filiación por parte del autor, a través de la cual se atisba una cierta intención de legitimar la novedad planteada a través del establecimiento de una remota - aunque en ocasiones no tan remota-conexión con formas y autores avaladas por su pertenencia al canon.

En esta segunda novela del Proyecto Nocilla parecen consolidarse los rasgos fundamentales que caracterizan la propuesta de Fernández Mallo: fragmentariedad, ruptura de la linealidad temporal, ausencia de una trama definida, apropiacionismo, tono superficial e irónico y mezcla impúdica de elementos de la alta cultura (alusiones a Jeff Koons), la cultura de masas (desde una canción pop al Gran Hermano), la filosofía (Wittgenstein) y la narrativa científica.

\subsection{Nocilla Lab (Alfaguara, 2009)}

La última parte de la trilogía de Mallo recoge, condensa e intensifica todo lo propuesto en las dos partes anteriores. Con un resultado discutible, el final del Proyecto Nocilla es algo así como el relato alucinado de un largo viaje que Mallo y "ella" — su pareja sin nombre- hacen a Cerdeña, para concluir algo que llaman el Proyecto.

Este proyecto funciona como una metáfora de no se sabe bien qué, pero que parece emular la construcción una especie de artefacto artístico-literario que pretende abarcar toda la vida de los protagonistas, del mismo modo que, en la imagen borgiana, los cartógrafos se obsesionan con la absurda idea de la construcción de mapas a escala real. Del mismo modo que en el cuento de Borges, esta idea resulta absurda y finalmente es desechada tanto por el protagonista del relato como por el propio Fernández Mallo, que resultan ser la misma persona. $\mathrm{O}$ al menos, tienen el mismo nombre.

En el camino que va de la propuesta de finalizar el proyecto - que es el motivo del viaje que ambos personajes emprenden - hasta el abandono del mismo, la novela vuelve a darle vueltas a los recursos expuestos en los dos relatos anteriores. Los juegos entre realidad-ficción mediante la recreación casi circular de un episodio cuyo principio y fin están tan difusos como la propia historia - si es que la hay- que se nos narra, las reflexiones trascendentales disparadas a partir elementos totalmente prosaicos, como en Proust, pero sustituyendo la madalena como símbolo del recuerdo por una lata de Coca- 
cola - o una rebanada de pan con Nocilla - como pretexto para a la divagación en torno a la nada simbólica ${ }^{16}$.

Lo interesante, lo que nos deja este cierre del Proyecto Nocilla, por tanto, es una propuesta de plasmación narrativa de los presupuestos de la posmodernidad. Eso sí, con unos años de retraso. El imaginario Nocilla, aunque se presente como novedad, no dista demasiado de la ya en absoluto nueva imagen de la utopía profiláctica del imaginario tradicionalmente posmoderno. Es por este motivo que la propuesta de Fernández Mallo y, en consecuencia, la propuesta de la generación Nocilla, no interesa tanto como un planteamiento estético innovador - ya que tal vez no lo sea tanto- pero sí resulta interesante por el lugar incómodo y, por tanto, crítico que esta ocupa en el panorama narrativo español actual.

El cierre de la novela y, por tanto del proyecto narrativo de Mallo, es un cómic en el que se representa una solitaria plataforma petrolífera cuyo único habitante es Enrique VilaMatas, que acoge a otro personaje que llega a nado y a pesar de afirmar que no sabe cuál es su nombre, se trata del propio Fernández Mallo. Vila Matas le muestra esa plataforma solitaria que es páramo y refugio contra la tormenta que se acerca, mientras le asegura que él llegó a ese páramo "porque quería dejar de escribir, desaparecer". "Ah, yo también escribía, y también me gustaría desaparecer", dice el otro personaje, el supuesto Fernández Mallo. "Ha venido al lugar adecuado", responde Vila Matas - atención al detalle- con un el puño sobre un ejemplar de la revista Vanity Fair, tapando el "fair" y dejando a la vista únicamente la palabra "vanity". Entonces, Mallo le pregunta sobre lo último que escribió, y Vila Matas le cuenta la historia de un preso que vive sin reloj dentro de una celda desde la que únicamente se ve el cielo, hasta que alguien, desde fuera, hace un agujero en la pared del cubículo en el que se encuentra, y le insta a salir de él con la frase "Entre, le estábamos esperando". Es ostensible aquí el guiño a la filiación literaria que propone la novela en su cierre: la identificación, en este sentido, con una literatura antirrepresentacional, del silencio, donde la verborrea final conduce a la desintegración de la palabra en imagen.

La última escena de la novela: una imagen de ellos dos, Vila Matas y Fernández Mallo, sentados alrededor de una pequeña mesa en el centro de una plataforma petrolífera

${ }^{16}$ Recordemos aquí la reflexión de Fernández Porta, que situaba el debate de la narrativa contemporánea en un dilema esencial: la nada como índice del vacío o la nada como índice de plenitud. Es evidente que Fernández Mallo, como buena parte de los autores vinculados a esta nueva forma de narrar visibilizada por la generación Nocilla, opta por la segunda opción, retomando desde la narrativa las reflexiones centrales del debate sobre la Posmodernidad. Esta recuperación tardía de la estética posmoderna en el marco de la narrativa española, es uno de los argumentos centrales que los autores de la Nocilla esgrimen para señalar el estancamiento que la narrativa española desde los 80, momento en que esta estética había cuajado ya en buena parte de las tradiciones narrativas occidentales, menos en la nuestra (Mora, 2007). 
perdida en la inmensidad del océano. La interpretación, por supuesto, queda totalmente abierta, como el conjunto de la obra, pero no es difícil intuir en ella cierta reflexión crítica en torno al lugar de la narrativa, de la literatura, hoy.

\section{Conclusiones. Una lectura de la propuesta Nocilla.}

Dicho todo esto, volvamos a nuestro punto de partida, y recordemos las líneas de sentido en las que ubicábamos nuestra reflexión en torno a la propuesta narrativa de la generación Nocilla. Más allá de su formulación como generación literaria y de esas ideas de "originalidad" y "novedad" que ha usado el mercado editorial para comercializarla, la propuesta Nocilla nos interesa, decíamos, porque supone la visibilización de un posicionamiento crítico con respecto a la tradición literaria que merece ser analizado y pensado con detenimiento por sus implicaciones en la evolución de una tendencia, hoy por hoy, muy importante en el panorama de la narrativa española estrictamente contemporánea. Esta tendencia se ubica en la línea del desarrollo de la novela española posmoderna que parece apuntar hacia la novela posmoderna norteamericana como uno de sus principales referentes. ${ }^{17}$

Tras haber reflexionado con un mínimo rigor sobre el fenómeno Nocilla, surge una idea que nos parece central a la hora de articular una radiografía estética e ideológica de las implicaciones de esta propuesta literaria que, como ya hemos mencionado más arriba, entendemos como una manifestación literaria del proceso de transformación cultural en la Era de la Información. Se trata de la idea de contradicción entendida como el principal signo de nuestro presente, a partir de la cual se hace urgente un análisis que permita llevar a cabo la reflexión en torno a su estetización como una respuesta a ciertos problemas culturales todavía sin resolver. En esta dirección se enmarcan las líneas de sentido de nuestra reflexión sobre los planteamientos estéticos e ideológicos de la propuesta narrativa de la generación Nocilla.

La insistencia de los propios miembros del grupo en presentar su obra como un objeto original e inédito y como una reacción de corte vanguardista hacia el panorama literario inmediatamente anterior y contemporáneo es, tal vez, el principal inconveniente que presenta esta propuesta para ser tomada en serio. En este sentido, existe además una contradicción entre la ostentación de una despectividad casi postiza con respecto a esta norma ya que el resultado último de esta propuesta ha sido, según la hipótesis aquí defendida, la progresiva - y perseguida - entrada en el canon narrativo español.

17 Buena parte de los autores que están publicando, hoy, novelas que apuntan en esta dirección Juan Francisco Ferré (Karnaval, 2012), Javier Calvo (El jardín colgante, 2012), Rodrigo Fresán (El fondo del cielo, 2009), etc.- remarcan su identificación con autores norteamericanos como David Foster Wallace o Thomas Pynchon, en lo que parece una voluntad de filiación estética, como decíamos, con la novela americana posmoderna más canónica. 
Esta idea de despectividad casi postiza trae a colación dos cuestiones que, de algún modo, desautorizan o, cuanto menos, problematizan la propuesta Nocilla como propuesta literaria. La primera, que en la actitud de algunos de estos autores puede llegar a atisbarse cierto gesto de malditismo impostado, como un simple reclamo de atención o incluso ciertas ganas de épater, de incomodar el estatuto de un canon tal vez demasiado autocomplaciente y ensimismado. La segunda, que en esa feroz crítica al canon se deja entrever una voluntad de formar parte de él, lo cual se ha ido haciendo evidente con el paso del tiempo, en la medida en que los autores vinculados a estas propuestas han ido ocupando posiciones privilegiadas en el panorama editorial español, como lo prueba la trayectoria editorial de la mayoría de ellos ${ }^{18}$. Lo que ha supuesto la incorporación de estos autores a las filas de las editoriales punteras del mercado español ha sido la irrupción de un discurso hipermoderno e hipermodernizado inusual, hasta el momento, en nuestra tradición narrativa. Esta irrupción ha sido, en esencia, el objetivo de la propuesta de la generación Nocilla.

Recordemos, ahora, el reto que nos planteábamos al inicio de este trabajo: entender la aparición de ciertas novedades literarias ya no desde su valor estético intrínseco -que en el caso de la generación Nocilla es, con frecuencia, más que cuestionable- sino desde el interés que algunas de estas novedades tienen para señalar, en este caso, el proceso de la globalización y el desarrollo de las tecnologías de la comunicación como factores radicalmente transformadores de las formas de subjetividad. Retomemos, también, el sentido de las interrogaciones con las que abríamos esta reflexión, en las que nos preguntábamos sobre la relación entre la emergencia de estas nuevas formas de subjetividad y cómo la literatura, a través del desarrollo de nuevas formas de creatividad y de la gestión de la misma por parte del mercado, las hace representables y, de hecho, las representa. Ofrecemos aquí nuestra reflexión sobre la generación Nocilla y su propuesta narrativa como un ejemplo en el que parecen cristalizar algunas posibles respuestas en relación a estas preguntas.

Fredric Jameson hablaba a principios de los años noventa de la imposición de una nueva subjetividad en la cultura producida en las sociedades neoliberales, en el marco de lo que él llamaba capitalismo tardío (Jameson, 1991). La consecuencia de la imposición de esta nueva superficialidad parece ser una operación de inversión ideológica que lleva a la reivindicación de una estética que resulta desafiante por la dificultad que conlleva tratar de encajarla en los marcos ideológicos que han sido operativos hasta hoy. Marcos ideológicos

\footnotetext{
${ }^{18}$ Recordemos el significativo cambio en la tendencia de autores como Agustín Fernández Mallo, Eloy Fernández Porta o Vicente Luis Mora de dejar de publicar en las editoriales minoritarias en las que empezaron para publicar directamente sus novedades en Alfaguara, Anagrama o Seix Barral, las editoriales punteras del mercado español.
} 
como, por ejemplo, el que insta a la crítica a calificar los textos de forma recurrente como conservador o subversivo, cuando la frontera entre ambos polos resulta cada vez más difusa y además, subjetiva. En este sentido, el interés de estas formas radica, más que nunca, en su lectura como síntoma de una forma subjetiva de entender en la transformación cultural de la que hablábamos más arriba; una transformación cultural que impone la imagen como condicionante de su contenido, una transformación que imprime también en la literatura, un valor de superficie.

Es importante destacar la gestión de esta inversión ideológica desde el plano del texto, en relación con el posicionamiento que la generación Nocilla toma con respecto al canon vanguardista, ya que es precisamente a través de la torsión de una serie de recursos retomados de la vanguardia y de la neovanguardia que podemos esbozar la deriva de su sentido ideológico original hacia una aparente desactivación política del discurso vanguardista, que ha llegado a generar términos tan contradictorios como "dadaísmo aideológico" (Fernández Mallo, 2009: 39) y afirmaciones tan cerca del oxímoron como considerar la nada un índice de plenitud (Fernández Porta, 2007: 43).

En el marco del debate en torno a los mecanismos de activación y desactivación política de la herencia estética vanguardista - uno de los debates estéticos más presentes en la actualidad - la literatura apunta de forma muy clara a un cambio de paradigma con respecto a las formas tradicionales de intertextualidad, que podría ser la consecuencia, a su vez, de un cambio de paradigma en la relación de equivalencia que parece establecerse entre los ejes del Tiempo, el Pasado y la Historia. La propuesta Nocilla esboza, en este sentido, una relación conflictiva con el pasado a través del desarrollo de ciertos recursos a nivel textual, de ahí el polémico apropiacionismo como reformulación y superación de la intertextualidad que, en tanto que técnica narrativa, pone de relevancia hasta qué punto el uso de las formas del pasado queda totalmente despojado, aquí, de toda idea de conflicto. Un ejemplo de esto es, como hace Fernández Mallo en todas y cada una sus obras, retomar figuras como José Ángel Valente, Juan Benet o Juan Goytisolo —-máximos exponentes de la neovanguardia en la narrativa española - como referentes literarios declarados en la forma, pero despojando esas formas de su contenido político original. La tradición queda, de este modo, despojada del valor cultural, y del mismo modo, el pasado como imagen queda despojado de un sentido concreto. También en esta línea, otra consecuencia de este vaciamiento de sentido en el uso de las formas del pasado es la pérdida de la autoría en términos históricos, que en el caso de Fernández Mallo y su El Hacedor. Remake (Alfaguara, 2011), llegó a convertirse en un conflicto legal con María Kodama, viuda de Jorge Luis Borges.

Ahora bien, ¿debemos entender en este posicionamiento literario que propone la generación Nocilla la articulación de una huída del conflicto histórico en el plano de la 


\section{Violeta Ros Ferrer}

narrativa? ¿ $\mathrm{O}$ tal vez, esta huída hunda sus raíces más profundas en una reacción contra esa idea de consenso que ha articulado la cultura y la literatura española de las últimas tres décadas?

Tras esta pregunta se articula, tal vez, la clave para entender la interacción entre creatividad, mercado y poder por la que nos preguntábamos más arriba. En esta interacción, las operaciones del mercado editorial articulan una lógica de consumo que diseña a la medida del propio mercado un público consumidor de novedades literarias. La propuesta literaria de la generación Nocilla se ha desarrollado en un espacio que la propia contradicción del sistema literario, como subproducto del social, ha dejado abierta. Y es precisamente de la comercialización de esta contradicción de lo que el mercado editorial español se ha valido para beneficiarse de la fórmula Nocilla.

La traducción de todas estas cuestiones se materializa en un violentamiento del sentido y de las formas a nivel textual. En esta dirección pueden entenderse las propuestas que surgen de esta fórmula, cuya articulación en el plano de la narrativa española está en la base de las implicaciones literarias de la transformación cultural. 


\section{Bibliografía citada}

Calvo, Javier. "La historia de la Nocilla". La Vanguardia, 26/09/07.

Calvo, Javier (2012). El jardín colgante. Barcelona: Seix Barral.

Castells, Manuel (2012). La era de la información. Economía, sociedad y cultura. México D.D: Siglo XXI.

Cifuentes Aldunate, Claudio (2012). "La a-historicidad de la novela del fragmento: de Rayuela a Nocilla Dream". Hansen, Hans Lauge y Cruz Suárez, Juan Carlos (eds.) La memoria novelada. Hibridación de géneros y metaficción en la novela española sobre la Guerra Civil y el franquismo (2000-2010). Bern: Peter Lang.

Fernández Porta, Eloy (2007). Afterpop. La literatura de la implosión mediática. Córdoba: Berenice.

Fernández Mallo, Agustín. "El hombre que salió de la tarta".

Fernández Mallo, Agustín (2006). Nocilla Dream. Barcelona: Candaya.

Fernández Mallo, Agustín (2008). Nocilla Experience. Madrid: Alfaguara.

Fernández Mallo, Agustín (2009). Nocilla Lab. Madrid: Alfaguara.

Fernández Mallo, Agustín (2009). Postpoesía. Hacia un nuevo paradigma. Barcelona: Anagrama.

Fernández Mallo, Agustín (2011). El hacedor de Borges. Remake. Madrid: Alfaguara.

Ferré, Juan Francisco (2012). Karnaval. Barcelona: Anagrama.

Fresán, Rodrigo (2009). El fondo del cielo. Barcelona: Mondadori.

Fuguet, Alberto y Gómez, Serio (1996). McOndo. Barcelona: Mondadori.

Jameson, Friedric (1991). El posmodernismo o la lógica cultural del capitalismo avanzado. Barcelona: Paidós.

LeDuff, Charlie. "Un árbol de zapatos crece en una solitaria ruta del desierto". El País, suplemento semanal The New York Times, 04/06/04: 6.

Maldonado, Tryno (ed.) (2008). Grandes Hits. Nueva generación de narradores mexicanos. vol.1, Oaxaca: Almadía.

Mora, Vicente Luis (2007). La luz nueva. Singularidades en la narrativa española actual. Córdoba: Berenice.

Oleza, Joan (2012): Trazas y bazas de la modernidad. Ensayos desde el cambio cultural. La Plata: Ediciones del lado de acá.

Ortega, Julio y Ferré, Juan Francisco (2005). Mutantes. Narrativa de última generación. Córdoba: Berenice. 
Violeta Ros Ferrer

Riaño, Pieio H. "Llámalo Nocilla". Diario Público, 10/03/2008.

VV.AA. "Dossier de novela española". Quimera 313 (2009): 26-49.

VV.AA (2012). CT o Cultura de la Transición. Barcelona: Mondadori.

Vilas, Manuel (2008). España. Barcelona: DVD. 